\title{
Liquid Flame Spray-A Hydrogen-Oxygen Flame Based Method for Nanoparticle Synthesis and Functional Nanocoatings ${ }^{\dagger}$
}

\author{
Jyrki M. Mäkelä*, Janne Haapanen, Juha Harra, Paxton Juuti and Sonja Kujanpää \\ ${ }^{1}$ Aerosol Physics Laboratory, Department of Physics, Tampere University of Technology, Finland
}

\begin{abstract}
In this review article, a specific flame spray pyrolysis method, Liquid Flame Spray (LFS), is introduced to produce nanoparticles using a coflow type hydrogen-oxygen flame utilizing pneumatically sprayed liquid precursor. This method has been widely used in several applications due to its characteristic features, from producing nanopowders and nanostructured functional coatings to colouring of art glass and generating test aerosols. These special characteristics will be described via the example applications where the LFS has been applied in the past 20 years.
\end{abstract}

Keywords: nanopowder, nanoparticle, functional coatings, flame spray pyrolysis, aerosol

\section{Introduction}

Nanoparticle powder materials are widely used in the modern industry, they have a variety of technological applications, they are commercially available but frequently custom made for each application using various fabrication methods (Kruis et al., 1998). Thermal gas phase synthesis and particularly aerosol techniques, offer ways to generate nanoparticles via dry industrial processes (Ulrich, 1971; Kruis et al., 1998). Especially flame methods are considered to be optimal for up-scaling (Kammler et al., 2001a; Stark and Pratsinis, 2002; Mueller et al., 2003). Thorough reviews on the flame spray pyrolysis (FSP) techniques for producing nanopowder have been made previously (Pratsinis, 1998; Mädler, 2004; Teoh et al., 2010). The FSP method generates well-defined nanoparticulate material which can be collected as a powder from the exhaust aerosol of the flame (Stepuk et al., 2013; Park and Park, 2015) or sprayed on a surface (Mishra et al., 2014). Apart from nanopowder production, recently the FSP and related techniques have also been used fairly efficiently in various types of coating applications (Mädler et al., 2006a; Tricoli et al., 2008; Pimenoff et al., 2009). With moderately high production rate (ca. $\mathrm{g} / \mathrm{min}$ ), the method is also applicable for covering large surface areas

Received 23 May 2016; Accepted 18 August 2016

P.O.Box 692, FI-33101 Tampere, Finland

* Corresponding author: Jyrki M. Mäkelä;

E-mail: jyrki.makela@tut.fi

TEL: +358-40-198-1018 with thin nanoparticle coating. One of the most recent applications is coating of a heat-sensitive flexible roll-to-roll material, such as paper or paper board, by a direct deposition of flame-generated nanoparticles in order to e.g. adjust the wetting properties of the substrate (Mäkelä et al., 2011; Haapanen et al., 2015).

In this review article, we introduce a distinct FSP technique, Liquid Flame Spray (LFS), which is based on a coflow type hydrogen-oxygen flame. It utilizes pneumatic spraying of a liquid precursor in the burner. Most often hydrogen is used as the atomizing gas, which having a high speed leads to a highly turbulent flame. The turbulent flame in the LFS is steady and robust, it does not require additional side flamelets and, due to the hydrogen, the precursor liquid itself does not need to be a fuel. The LFS has been widely used in several applications due to its characteristic features. Additionally to powder generation and coating applications, the LFS is also feasible as a test aerosol generator, since the utilization of hydrogen as the fuel, the exhaust gas does not contain excessive amounts of carbon containing components. In this review article, these special characteristics will be described via the example applications in which the LFS has been applied in the past 20 years.

\section{Method description}

Flame spray pyrolysis (FSP), or liquid feed flame spray pyrolysis, is usually defined as a method consisting of a spray of micron-sized liquid precursor droplets and a 


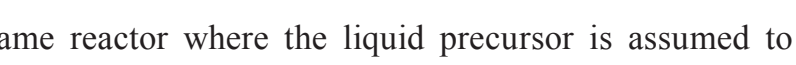
exaporate, react and nucleate into nanoparticulate form, as described by e.g. Ulrich (1984), Pratsinis (1998) and Teoh et al. (2010). The history of the FSP has recently been described on a more general level by e.g. Purwanto et al. (2011) and Trommer and Bergmann (2015). The several alternative reaction schemes and particle formation mechanisms occurring in the FSP reactor when fabricating, e.g., metal oxide powder, has been discussed on a general level by Mädler (2004).

We define Liquid Flame Spray (LFS) as one certain type of flame spray pyrolysis, where the combustion gas and oxidizing gas are hydrogen and oxygen, respectively. It is specific, that the combustion gas is also acting as an atomizing gas and no other gaseous components are necessarily needed in the process. It is notable that hydrogen driven flames have also been widely used and studied elsewhere, and utilized by e.g. Sokolowski et al. (1977), Chung and Katz (1985), Cho and Choi (2000), Lee and Choi (2000), and Katusic and Krauss (2011).

The term 'Liquid Flame Spray' was originally used by Tikkanen et al. (1994), Tikkanen et al. (1997) and Gross et al. (1999) in connection with an application where art glass was coloured by nanoparticles deposited from the flame onto the surface of a molten glass item. In this article, we have maintained this definition that LFS consists of a liquid precursor atomization by one of the combustion gases, favourably $\mathrm{H}_{2}$. This is not an unambiguous definition but it clarifies the division within the family of several flame spray pyrolysis modifications in literature, also described by e.g. Trommer and Bergmann (2015). With this in mind, we have collected Table 1 to list up papers dealing with LFS, or a very similar technique.

The basic characteristics of the LFS process have been presented by Tikkanen et al. (1997) and Aromaa et al. (2007), and the process fundamentals have been further discussed by Pitkänen et al. (2005), Keskinen et al. (2007a) and Keskinen et al. (2008). A schematic of the LFS-burner is presented in Fig. 1.

In the burner nozzle, the speed of the hydrogen flow, as an atomizing gas, is close to the speed of sound. This is advantageous for the atomizing process, as it assists in maximizing the kinetic energy input into the atomizer, where generally small precursor droplets are assumed to be favourable to facilitate evaporation from the droplets. Keskinen et al. (2008) have measured the droplet size distribution of the LFS atomizer with a conclusion that by number, the majority of the generated droplets are in the submicron size range, mass median diameter being at around 3-5 $\mu \mathrm{m}$.

According to the data by Tikkanen et al. (1997), Pitkänen et al. (2005), Mäkelä et al. (2006) and Keskinen et al. (2007a), the maximum temperature of the LFS flame exceeds $2600 \mathrm{~K}$. A temperature profile obtained with typ-

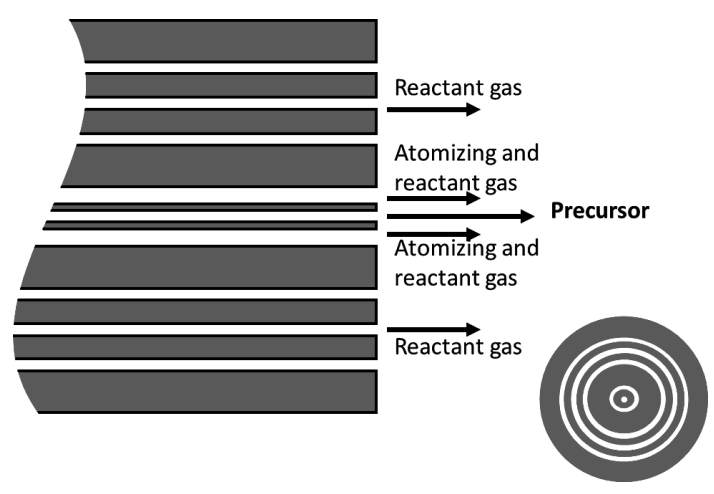

Fig. 1 Liquid Flame Spray burner. Note, that only two of the available coaxial rings for gas flow are necessary for the basic performance of the LFS-method. The rest of the rings may be used to modify the flame or to introduce additional components into the process.

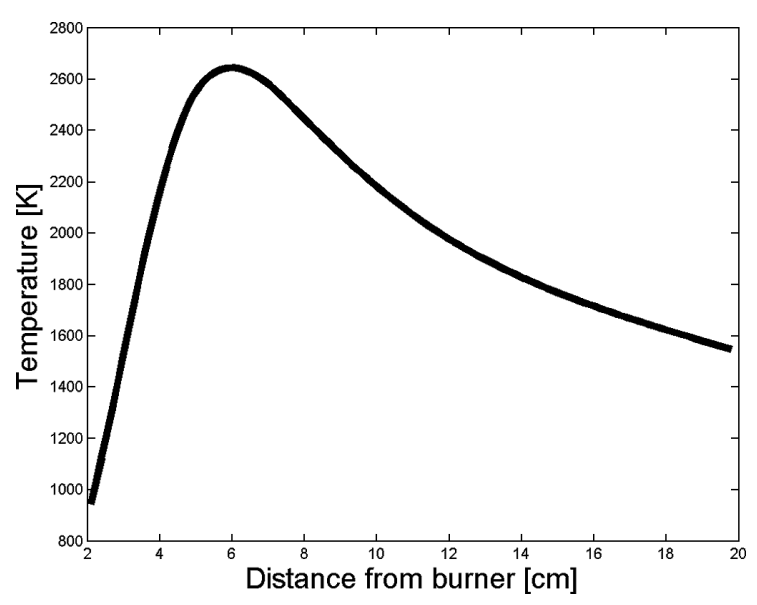

Fig. 2 Temperature in the center axis of a LFS flame with gas volume flow rates of $\mathrm{H}_{2} / \mathrm{O}_{2}=20 / 10 \mathrm{l} / \mathrm{min}$. According to data from Pitkänen et al. (2005).

ical gas volume flow rates, $\left(\mathrm{H}_{2} / \mathrm{O}_{2}=20 / 10 \mathrm{l} / \mathrm{min}\right)$ is presented in Fig. 2 (Pitkänen et al., 2005). This relatively high temperature level is, again, advantageous to facilitate precursor evaporation and decomposition. Eventually, it is apparent that the variety of feasible precursor liquids that are accessible to the LFS is fairly large.

In most of the studies on the LFS, the ratio of hydrogen and oxygen flow rates has been typically stoichiometric, $2 / 1$, but it can also be easily varied. In the studies by both Cho and Choi (2000) and Lee and Choi (2000) on relatively similar oxy-hydrogen flames, the amount of hydrogen was decreased well below the stoichiometric value. When hydrogen flow rate was varied in the order of $10 \%$ of $\mathrm{O}_{2}$, both the flame temperature, increasing with the fraction of $\mathrm{H}_{2}$, and the crystal structure of the generated particles were changed. Similar approach with varying $\mathrm{H}_{2} / \mathrm{O}_{2}$ ratio have been described also by e.g. Kammler et al. (2001b), Hannebauer and Mezel (2003), Dosev et al. (2006), Goldys et al., (2006), Jang et al. (2006), Pikhitsa et al., (2007). Sheen et al. (2009) used an oxy-hydrogen 
Table $1 \mathrm{~K}^{\circ}$ Collection of articles utilizing liquid feed-flame spray pyrolysis combined with $\mathrm{H}_{2} / \mathrm{O}_{2}$-flame

\begin{tabular}{|c|c|c|c|}
\hline Reference & Particle compound & Application & Specific \\
\hline Tikkanen et al., 1997, Surface and Coatings Technol. & $\mathrm{Al}_{2} \mathrm{O}_{3}$ & Process fundamentals & \\
\hline Pitkänen et al., 2005, IFRF Combustion Journal & $\mathrm{SiO}_{2}$ & Process fundamentals & \\
\hline Aromaa et al., 2007, Biomolecular Engineering & $\mathrm{TiO}_{2}$ & Process fundamentals & \\
\hline Aromaa et al., 2013, A Nanotechnol Approach, Wiley & $\mathrm{Ag}, \mathrm{TiO}_{2}$ & Process fundamentals & \\
\hline Cho and Choi, 2000, Journal of Aerosol Science. & $\mathrm{SiO}_{2}$ & Process fundamentals & $\mathrm{SiCl}_{4}$-precursor \\
\hline Chung and Katz, 1985, Combustion and Flame & $\mathrm{SiO}_{2}$ & Process fundamentals & $\mathrm{H}_{2} / \mathrm{O}_{2} / \mathrm{Ar}$ counterflow flame \\
\hline Harra et al., 2015, Aerosol Science and Technol. & $\mathrm{SiO}_{2}, \mathrm{TiO}_{2}$ & Process fundamentals & Powder form LFS \\
\hline Harra et al., 2016, AIChE Journal & $\mathrm{Al}_{2} \mathrm{O}_{3}$ & Process fundamentals & Residual particles \\
\hline Keskinen et al., 2008, Atomization and Sprays & $\mathrm{ZrO}_{2}$ & Process fundamentals & Spray droplets \\
\hline Lee and Choi, 2000, Journal of Aerosol Science & $\mathrm{SiO}_{2}$ & Process fundamentals & $\mathrm{SiCl}_{4}$-precursor \\
\hline Katusic and Kress 2011, Patent CA2803211 A1. & $\mathrm{Ni}_{\mathrm{x}} \mathrm{O}_{\mathrm{y}}, \mathrm{Mn}_{\mathrm{x}} \mathrm{O}_{\mathrm{y}} \mathrm{Co}_{\mathrm{x}} \mathrm{O}_{\mathrm{y}}$ & Powder generation & \\
\hline Keskinen et al., 2004, Journal of Materials Res. & $\mathrm{Ag}, \mathrm{Pd}$ & Powder generation & \\
\hline Sokolowski et al., 1977, Journal of Aerosol Science & $\mathrm{Al}_{2} \mathrm{O}_{3}$ & Powder and aerosol generation & \\
\hline Harra et al., 2013, Powder Technology & $\mathrm{Fe}_{\mathrm{x}} \mathrm{O}_{\mathrm{y}}$ & Powder generation & Photocatalysis \\
\hline Hartmann et al., 1985, US Patent & $\mathrm{TiO}_{2} \mathrm{SiO}_{2}, \mathrm{Al}_{2} \mathrm{O}_{3}$ & Powder generation & \\
\hline Keskinen et al., 2009, Journal of Applied Physics & $\mathrm{SnO}_{2}$ & Powder generation & Gas sensors \\
\hline Mäkelä et al., 2004, Journal of Materials Science & $\mathrm{Ag}, \mathrm{Pd}, \mathrm{Fe}_{\mathrm{x}} \mathrm{O}_{\mathrm{y}}$ & Powder generation & \\
\hline Nikkanen et al., 2008, Res. Lett. Nanotechnol & $\mathrm{Al}_{2} \mathrm{O}_{3}, \mathrm{ZrO}_{2}, \mathrm{Fe}_{\mathrm{x}} \mathrm{O}_{\mathrm{y}}$ & Powder generation & \\
\hline Nikkanen et a., 2014, Powder Technology & $\mathrm{Al}_{2} \mathrm{O}_{3}, \mathrm{ZrO}_{2}, \mathrm{Fe}_{\mathrm{x}} \mathrm{O}_{\mathrm{y}}$ & Powder generation & \\
\hline Dosev et al., 2006, J Aerosol Sci. & $\mathrm{Eu}: \mathrm{Y}_{2} \mathrm{O}_{3}$ & Powder generation & Photoluminescence \\
\hline Goldys et al., 2006, J Am Chem Soc. & Er: $\mathrm{Gd}_{2} \mathrm{O}_{3}$ & Powder generation & Fluorescence \\
\hline Keskinen et al., 2007b, Catalysis Letters & $\mathrm{Pd}, \mathrm{Al}_{2} \mathrm{O}_{3}, \mathrm{La}_{2} \mathrm{O}_{3}$ & Nanoparticle suspension & Catalysis \\
\hline Mäkelä et al., 2006, Materials Letters & $\mathrm{TiO}_{2}$ & Deposit & \\
\hline Sainiemi et al., 2007, Nanotechnology & $\mathrm{SiO}_{2}$ & Deposit & Etching mask \\
\hline Thybo et al., 2004, J Catalysis & $\mathrm{Au} / \mathrm{TiO}_{2}$ & Deposit & Catalysis \\
\hline Keskinen et al., 2007a, J. of Nanoparticle Research & $\mathrm{Ag}, \mathrm{TiO}_{2}$ & Deposit, Aerosol & Binary particles \\
\hline Tikkanen et al., 1994, J. of Non-Crystalline Solids & $\mathrm{CuO}$ & Class colouring & Coloured glass powder in liquid \\
\hline Beneq Oy, 2016, Glass Coloration & $\mathrm{CoO}, \mathrm{Co}_{3} \mathrm{O}_{4}, \mathrm{CuO}, \mathrm{Ag}$ & Glass colouring & \\
\hline Gross et al., 1999, J of Thermal Spray Technol. & $\mathrm{CoO}, \mathrm{Co}_{3} \mathrm{O}_{4}, \mathrm{CuO}, \mathrm{Ag}$ & Glass colouring & \\
\hline Hotoleanu et al., 2002, NOC 2002 & $\mathrm{SiO}_{2}, \mathrm{Al}_{2} \mathrm{O}_{3}, \mathrm{Er}_{2} \mathrm{O}_{3}$ & Optical fiber & \\
\hline Rajala et al., 2003, Rev. Advanced Materials Sci. & $\mathrm{La}_{2} \mathrm{O}_{3}, \mathrm{SiO}_{2}, \mathrm{Er}_{2} \mathrm{O}_{3}, \mathrm{Al}_{2} \mathrm{O}_{3}$ & Optical fiber & Glass \\
\hline Tammela et al., 2006, Proceedings of SPIE 6116 & $\mathrm{SiO}_{2}, \mathrm{Al}_{2} \mathrm{O}_{3}, \mathrm{Er}_{2} \mathrm{O}_{3}$ & Optical fiber & \\
\hline Keskinen et al., 2006, Catalysis Letters & $\mathrm{Ag}, \mathrm{TiO}_{2}$ & Functional coating & Anti-bacterial \\
\hline Ejenstam et al., 2015b, Applied Surface Science & $\mathrm{TiO}_{2}$ & Functional coating & Corrosion protection \\
\hline Piispanen et al., 2011, Applied Surface Science & $\mathrm{TiO}_{2}$ & Functional coating & Glass \\
\hline Pimenoff et al., 2009, Thin Solid Films & $\mathrm{TiO}_{2}$ & Functional coating & Glass, Wetting \\
\hline Stepien et al., 2013b, Wear & $\mathrm{TiO}_{2}$ & Functional coating & Mechanical \\
\hline Stepien et al., 2013c, Nanoscale Research Letters & $\mathrm{TiO}_{2}$ & Functional coating & Mechanical \\
\hline Valtakari et al., 2016, Nordic Pulp and Paper Res J. & $\mathrm{TiO}_{2}$ & Functional coating & Microfluidistics on board \\
\hline Songok et al., 2014, ACS Appl. Mater. and Interfaces & $\mathrm{TiO}_{2}$ & Functional coating & Microfluidistics on paper \\
\hline Keskinen et al., 2005, The Electrochemical Society & $\mathrm{TiO}_{2}$ & Functional coating & Photocatalysis \\
\hline Valtakari et al., 2013, J Print Media and Technol. Res. & $\mathrm{TiO}_{2}$ & Functional coating & Printing \\
\hline Aromaa et al., 2012, J Aerosol Science & $\mathrm{TiO}_{2}$ & Functional coating & Wetting \\
\hline Mäkelä et al., 2011, Aerosol Science and Technology & $\mathrm{TiO}_{2}$ & Functional coating & Wetting \\
\hline Moghaddam et al., 2015, Holzforschung & $\mathrm{TiO}_{2}$ & Functional coating & Wetting \\
\hline Stepien et al., 2011, Applied Surface Science & $\mathrm{TiO}_{2}$ & Functional coating & Wetting \\
\hline Stepien et al., 2013a, Langmuir & $\mathrm{TiO}_{2}$ & Functional coating & Wetting \\
\hline Teisala et al., 2010, Surface and Coatings Technology & $\mathrm{TiO}_{2}$ & Functional coating & Wetting \\
\hline Teisala et al. 2013a, Cellulose & $\mathrm{TiO}_{2}$ & Functional coating & Wetting \\
\hline Teisala et al., 2013b, Colloid and Polymer Science & $\mathrm{TiO}_{2}$ & Functional coating & Wetting \\
\hline Teisala et al., 2014a, Nordic Pulp and Paper Res J. & $\mathrm{SiO}_{2}, \mathrm{TiO}_{2}$ & Functional coating & Wetting \\
\hline Teisala et al., 2014b, Cellulose & $\mathrm{TiO}_{2}$ & Functional coating & Wetting \\
\hline Tuominen et al., 2014, J. Adhesion Sci. Technol. & $\mathrm{SiO}_{2}$ & Functional coating & Wetting \\
\hline Haapanen et al., 2015, Mater. Chem. Physics & $\mathrm{SiO}_{2}, \mathrm{TiO}_{2}$ & Functional coating & Wetting \\
\hline Teisala et al., 2012, Langmuir & $\mathrm{TiO}_{2}$ & Functional coating & Wetting fundamentals \\
\hline Stepien et al., 2012a, Surface and Coatings Technol. & $\mathrm{TiO}_{2}$ & Functional coating & Wetting; Surface chemistry \\
\hline Stepien et al., 2012b, Applied Surface Science & $\mathrm{SiO}_{2}, \mathrm{TiO}_{2}$ & Functional coating & Wetting; Surface chemistry \\
\hline
\end{tabular}


filine to produce coated particles of $\mathrm{SnO}_{2}, \mathrm{SiO}_{2}$ and $\mathrm{TiO}_{2}$, insinary combinations. Alternatively, if an excess amount of hydrogen will be injected, then the flame will create reducing conditions. In the study by Aromaa et al. (2012), it was found out that an excess amount of hydrogen in the flame may have an effect on the surface chemistry of the generated particles, and the amount of carbon/hydrocarbons on the surface. But in their case the product Ti-compound remained still in the form of $\mathrm{TiO}_{2}$. Provided that the hydrogen flow is kept constant, size and temperature of the flame can be affected also by varying the solvent feed rate (Mäkelä et al., 2011), especially for the alcohol based precursors.

The atomization of the liquid precursor usually brings along another issue: the fate of the residue of each precursor droplet sprayed into the flame (Strobel and Pratsinis, 2011; Rosebrock et al., 2013; 2016). If the precursor liquid is sufficiently volatile, the original droplet will evaporate and a reaction in the gas phase will take place producing nanoparticles, as expected. If the precursor liquid is not volatile enough, then a liquid-to-solid reaction will take place in the droplet resulting in the formation of residual particles, as described in Fig. 3.

Depending on the properties of the liquid precursor, e.g. volatility, concentration and temperature of the decomposition, the remaining residual particles may be moderately

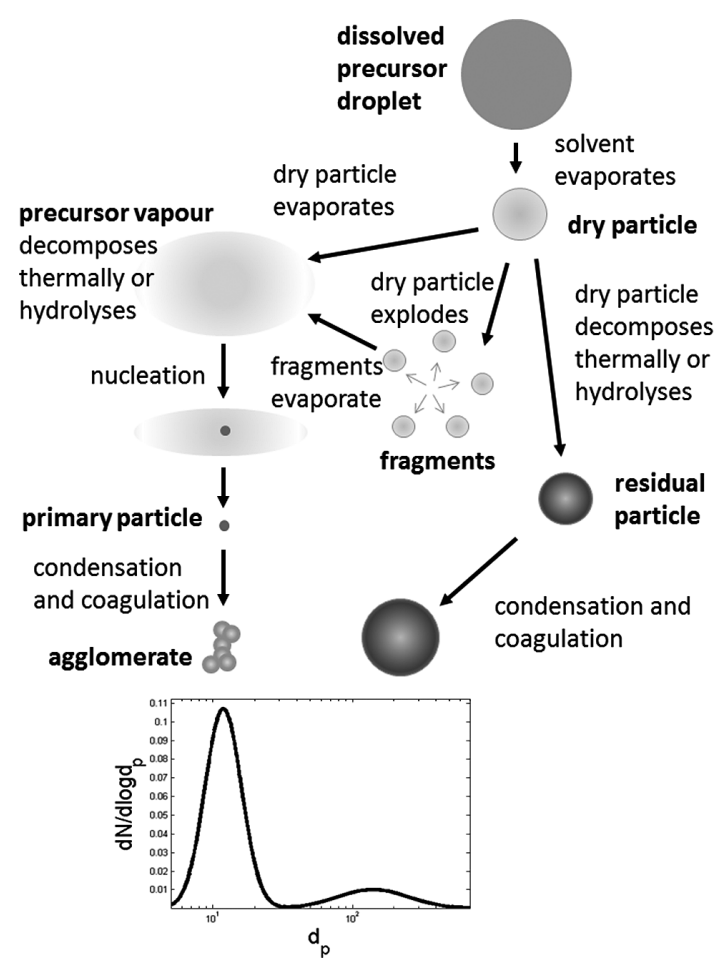

Fig. 3 Schematic of the particle formation mechanisms in a Liquid Flame Spray process. Both agglomerated nanoparticles and larger residual particles will be formed, resulting in a bimodal product particle size distribution. Updated from Aromaa et al. (2013). large. In the worst case, the residual particle diameter may remain in the order of $100 \mathrm{~nm}-1 \mu \mathrm{m}$. This is not by any means advantageous for the nanopowder production, since the specific surface area of the powder will inevitably be decreased. The importunate problem has recently been solved for the case of conventional methane/oxygen FSP-flame by introducing specific chemical components in the precursor to induce droplet explosion (Strobel and Pratsinis, 2011; Rosebock et al., 2013; Rosebock et al., 2016). In their case, DEGBE (diethylene glycol monobutyl ether) or EHA (2-ethylhexanoic acid) were introduced into the precursor liquid, using concentration levels of $50 \%$ for these chemicals. In the case of our hydrogen driven LFS, it was recently found out that already less than $5 \%$ of EHA in the precursor solution (containing aluminum nitrate) may be sufficient to induce the desired explosion of the precursor droplets, and thereby avoiding residual particle formation (Harra et al., 2016).

\section{Applications}

\subsection{Nanopowder generation}

The most widely used application of the FSP is the generation of nanopowders (Ulrich, 1971; Ulrich, 1984). The product material is most often collected by bag filters consisting of e.g. glass fiber material (Kammler et al., 2001a; Stark and Pratsinis, 2002). A commercial process by Degussa/Evonik utilizes a hydrogen-oxygen flame, similarly to the LFS, but typically gaseous precursors, such as $\mathrm{SiCl}_{4}$ and $\mathrm{TiCl}_{4}$ (Hartmann et al., 1995). Still, Evonik also uses a liquid fed FSP system, with a preference of hydrogen gas as a fuel, e.g. to produce nanopowders containing lithium compounds (Katusic and Kress, 2011).

The LFS has been used in nanopowder production for e.g. single component (Tikkanen et al., 1997; Mäkelä et al., 2004), binary component (Keskinen et al., 2004; Keskinen et al., 2005) and multicomponent nanopowders (Nikkanen et al., 2008; Nikkanen et al,. 2014). In these studies, the particulate matter was collected from the exhaust flow of the flame using an electrostatic precipitator.

Nikkanen et al. (2014) used collected and compacted composite nanopowder made by the LFS to fabricate carbon nanotubes within the porous powder sample. The LFS generated nanopowder has also been used for fabricating magnetic composite nanoparticles in a tube furnace (Harra et al., 2013), in order to produce photocatalytic powder for water purification, and for a study on coating of ceramic nanoparticles with silver in a tube furnace (Harra et al., 2015).

One consequence of the fuel being hydrogen is that the end product will be mostly water vapour. This fact can be utilized in the powder collection, as described by Keskinen 
posure chambers. The in situ production of nanoparticles in large quantities with a flame, with natural suspension into the air, is a much simpler and effective way to generate a well-defined nanoaerosol than to start with a commercial nanopowder and then de-agglomerate and disperse it into an airborne suspension (Mülhopt et al., 2007).

Monsé et al. $(2013 ; 2014)$ have characterized the LFS flame and its gaseous emissions in order to test and use it for exposure assessment. The $\mathrm{CO}_{2}$-emission of the LFS flame is rather small, since the only carbon source is the precursor itself (including solvent). This is advantageous compared to the conventional flames utilizing e.g. methane or acetylene. However, a slight disadvantage in this application arises from nitrogen oxides. If the LFS flame operates normally in the free atmospheric conditions, having immediate access to ambient oxygen in the surroundings of the flame, then, due to the thermal reactions, the $\mathrm{NO}_{\mathrm{x}}$ level in the exhaust gas can exceed $1.5 \mathrm{ppm}$ (Monsé et al., 2014). Whereas, the available excess oxygen is typically considered to be advantageous for the nanopowder generation to ensure complete oxidation of the product (Katusic and Kress, 2011), here the excess oxygen is not necessarily crucial. Monsé et al. (2014) succeeded in decreasing the $\mathrm{NO}_{\mathrm{x}}$ concentration level below the required $500 \mathrm{ppb}$ by arranging a sheath flow of inert gas around the flame. In their case, the argon flow introduced from the outmost ring in the annular coflow burner kept the flame apart from the oxygen of the ambient air, avoiding excess $\mathrm{NO}_{\mathrm{x}}$ formation.

Flame generator can also be used as a test aerosol source in several other purposes such as instrument testing (Mäkelä et al., 2009; Asbach et al., 2009) or filter loading experiments. Once the nanoparticle aerosol has been generated, both large scale industrial filters and smaller scale personal gas mask filters could be considered. In two recent studies (Koivisto et al., 2012; Koivisto et al., 2015), a potential inhalation dose and performance of a loose fitting respiratory filter were evaluated using particle size distribution and concentration data obtained from a LFS generated aerosol in a test room.

\subsection{Accumulation of particle deposit}

considered an openly operating particle source in an at mospheric pressure. In this respect, the flame can be considered as an exemplary case of a nanoparticle process or potentially also an aerosol source emulating airborne engineered nanoparticle (ENP) release in the workplace. In a typical scenario of occupational health, the particles are usually emitted from the process due to leaks in the ducts or processing chambers or other unintentional release from the process line into the laboratory. Flame technique is one of the most up-scalable techniques for generating nanoparticles to fill large containers for high-volume use of ENPs, or e.g. for arranging a flow split into several ex-

In some applications, as in catalysis, photocatalysis, or gas measurement, granular highly porous material is needed, in order to have large surface area available for reaction to occur on. However, these materials often require that certain degree of solidity needs to be maintained. The porous material for, e.g., gas sensing can be prepared by creating a viscous paste which contains the nanopowder and then performing an appropriate heat treatment to form the final material (Keskinen et al., 2009). The material could also be accumulated by direct 
depsosition of the nanoparticles from the gas phase (Aâdler et al., 2006a; Castillo et al., 2014; Liu et al., 2016).

In our case, the nanoparticle deposition process from the flame onto the substrate is mainly a combination of thermophoresis and diffusion through the boundary layer above the surface:

$$
J=-D \frac{\mathrm{d} N}{\mathrm{~d} x}-\frac{0.55 N \gamma_{\mathrm{gas}}}{\rho_{\mathrm{gas}}} \frac{1}{T} \frac{\mathrm{d} T}{\mathrm{~d} x}
$$

where $N$ denotes the particle number concentration, $x$ distance towards the substrate, $\gamma$ and $\rho$ the dynamic viscosity and density of the gas, respectively, and $D$ denotes the diffusion coefficient of the particles.

It is convenient to categorize the arrangements of the deposited nanoparticles on the substrate, depending on the morphology of the generated porous material. Fig. 5 illustrates schematics of some main alternatives. The particles are arranged on the substrate as a sub-monolayer either clearly separate (Fig. 5a) or somewhat closer and having contact with each other (Fig. 5b). Sainiemi et al. (2007) utilized these two options to create $\mathrm{SiO}_{2}$-nanoparticle mask for deep reactive ion etching of silicon wafer in order to fabricate nanopillars on the wafer surface. The particles may also form a porous layer either without sintering (Fig. 5c) or with sintering (Fig. 5d), or even form a thicker layer (Fig. 5e). Finally, the particles may also be embedded in the substrate (Fig. 5f), as may occur with softer substrates, such as e.g. polymer or molten glass. The heat of the flame assists the process keeping the substrate soft and thereby enhancing particle penetration into the substrate material. Using polymers as a deposition substrate for nanoparticles to fabricate polymer nanocom-

a)

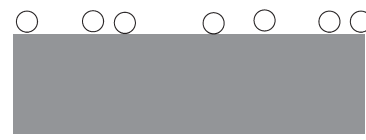

c)

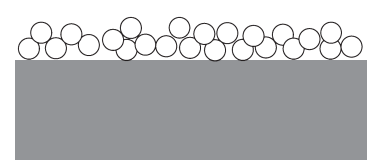

e)

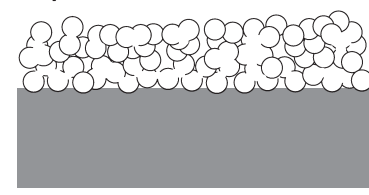

Fig. 5 Schematic illustration of different alternatives for morphology of the nanoparticle deposit. posites has a high potential for many applications. Recently e.g. plasmonic and phosphorescent-superparamagnetic actuators have been prepared by depositing nanoparticles from the flame into a polymer film (e.g. PMMA) and covering the nanoparticle film with spin coated layer of the same polymer as the substrate, resulting in a nanoparticle layer fully embedded in the polymer (Sotiriou et al., 2013). Also conductive polymer nanocomposites have been fabricated with similar process (Blattmann et al., 2015).

Of the alternatives described in Fig. 5a-f, the thin particle layers, such as shown in Fig. 5a-d, are possible to be deposited practically onto any material, since the interaction time with the flame and substrate can be very short. Two practical examples have been presented in Fig. 6a and Fig. 6b. If thicker nanoparticle layers are required, then high nanoparticle concentrations, intensive particle fluxes or longer deposition times are needed. For longer deposition time, it is often also required that the substrate stands heat of the flame relatively well.

The direct deposition process of the LFS generated nanoparticles, as described above, has been studied by Mäkelä et al. (2006), Keskinen et al. (2006) and Keskinen et al. (2007a). It is apparent that along with the accumulation of the nanoparticles, the porous material will be gradually deformed due to the heat treatment. In case of Mäkelä et al. (2006), it was observed that the collected $\mathrm{TiO}_{2}$, which originally consisted mostly of anatase, had a tendency to be converted into rutile due to the heat treatment during the deposition process. In Fig. 6, a layer of deposited $\mathrm{SiO}_{2}-\mathrm{Al}_{2} \mathrm{O}_{3}(90 \% / 10 \%)$ is shown in different

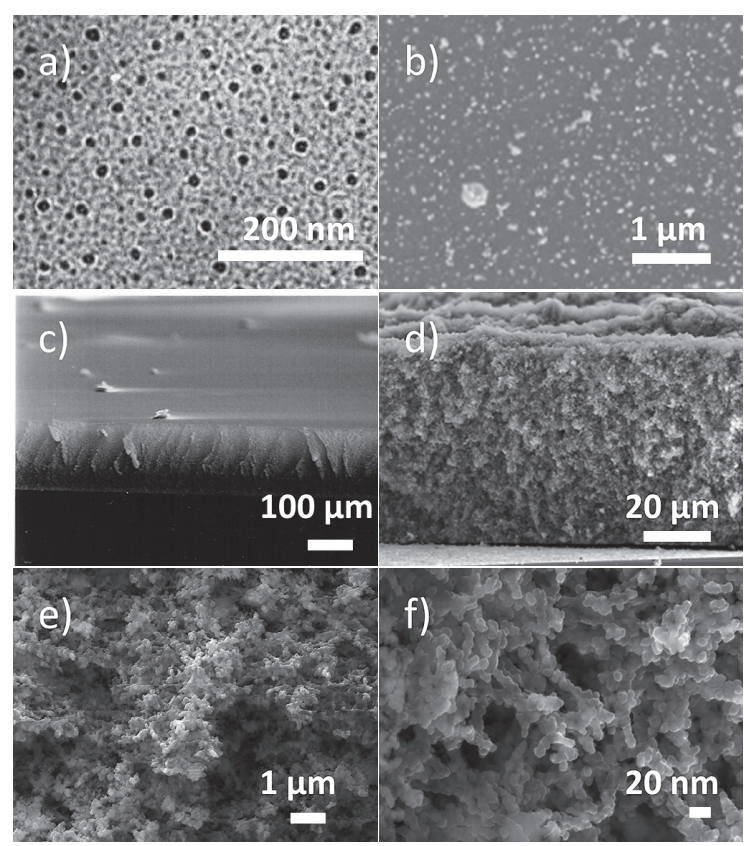

Fig. 6 a-b) Sub-monolayer types of silver nanoparticle deposits, $\mathbf{c}-\mathbf{f})$ Accumulation of a thicker porous $\mathrm{SiO}_{2}-\mathrm{Al}_{2} \mathrm{O}_{3}$ nanoparticle layer on a silicon wafer (Mäkelä, 2005). 
scales. For the largest magnifications, it is seen that a certain degree of sintering has occurred.

The sintering of the nanoparticles in a similar process, while fabricating nanostructured porous photocatalytic $\mathrm{TiO}_{2}$, has been further studied by Thimsen and Biswas (2007) and Thimsen et al. (2008), with a conclusion that the eventual sintering of the porous material under the flame is governed by both the sample temperature and the primary particle size, sintering being enhanced with increasing temperature and with decreasing primary particle size.

It is notable that this deposit of our LFS flame generated particles, shown in Fig. 6e-f, has a strikingly similar structure to the one presented by Mädler et al. (2006a), where also thermophoresis is the dominating deposition mechanism, but clearly differs from the more tree-like structure presented by Castillo et al. (2014), where diffusion clearly is the dominating deposition mechanism.

The assembling of the porous nanoparticle layer is highly dependent on the deposited particle morphology and the Peclet number of the flow field. (Mädler et al 2006; Nasiri et al., 2015) The layer thickness and porosity can be individually controlled as shown by e.g. Mädler et al. (2006b). Ballistic deposition of individual particles produces denser layers than those produced by letting agglomerates with low fractal dimension diffuse to the surface.

Comparison of the cross-sectional SEM image of LFSmade $\mathrm{TiO}_{2}$ layer by Stepien et al. (2013c) and simulations made by Mädler et al. (2006b) indicates that the LFSmade porous $\mathrm{TiO}_{2}$-nanoparticle layer consists of deposits of multiple agglomerates produced by flame process. Deposited agglomerates consist of several primary nanoparticles, forming thick layer of nanoparticles with high porosity.

\subsection{Glass colouring and processing}

In the early history of the LFS, properties of glass material were affected by the deposition of flame generated nanoparticles onto its surface. Here, both art glass colouring and amplifying optical fiber are discussed.

In Fig. 7a and Fig. 7b the principle of the art glass colouring has been presented. During the high temperature process in molten glass, it is assumed that the nanoparticle will first deposit and plunge into the glass (according to Fig. 5f), and then the metal compound will be dissolved into the glass matrix, and finally the ions will be diffused inside the glass material. A typical colouring agent is $\mathrm{CoO}_{3}$, which creates a strong blue colour within the soda-lime-silica glass due to dissolved $\mathrm{Co}^{2+}$ ions (Fig. 7b, Gross et al., 1999). The wavelength from the incoming light, which corresponds to the electronic transition of the metal ion, is absorbed in the glass and thus the
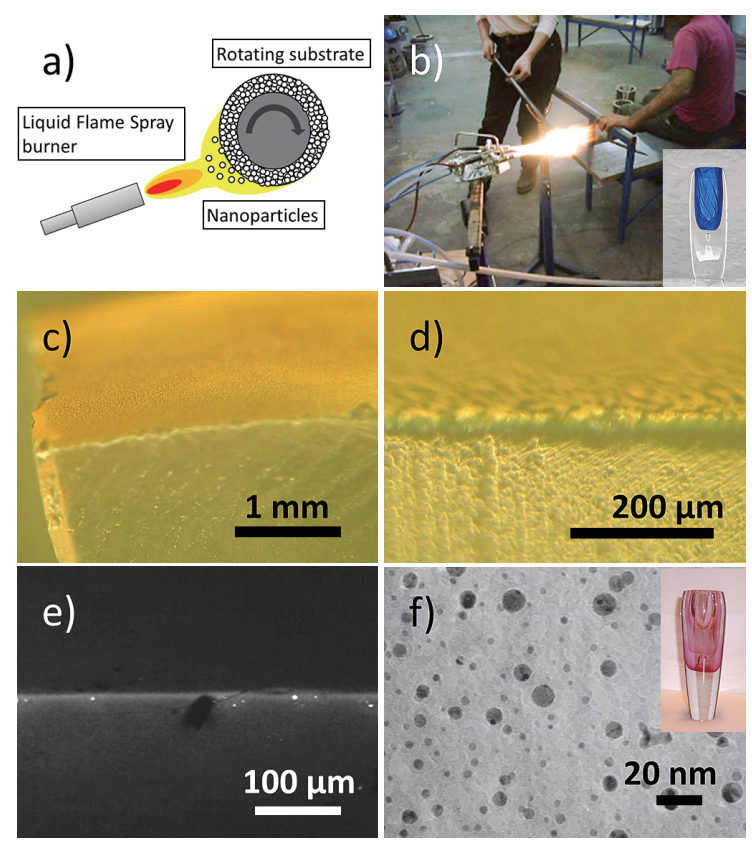

Fig. 7 Glass processing. a) Deposition of nanoparticles onto a rotating substrate, an art glass item or an optical fiber preform, b) glass colouring in practice, blue colour from $\mathrm{CoO}_{3}$ nanoparticles, $\mathbf{c}-\mathbf{d}$ ) optical micropraphs of a cross section of coloured yellow glass (Ag-nanoparticles), e) SEM backscattering graph of a cross section of coloured glass (Ag), f) TEM graph of in-flame sampled nanoparticles $(\mathrm{Au})$, used for red colour in glass item shown (in insert). Glasswear design by Markus Eerola.

imparting colour will be made up of the remaining wavelengths in the visible spectrum (Bamford, 1977). However, compounds such as silver (Fig. 7c-e) and gold (Fig. 7f) are known to dissolve and re-nucleate into reduced nanoparticles. There the colour effect will arise from light scattering from the nanoparticles in the glass matrix, being eventually dependent on the final size of the noble metal nanoparticles. In this application, where the LFS flame is in close contact with the glass substrate, the heat from the flame is an essential enabling feature of the process. The heat prevents the molten glass from cooling down temporarily and it also intensifies both the particle diffusion and dissolving inside the glass material. The LFS is also commercially applied in float glass colouring under the trademark nHALOC (Beneq, 2016).

There are also several other LFS applications related to optics, such as doped optical fiber fabrication (Rajala et al., 2003; Tammela et al., 2006), where one needs to be able to control the refractive index of the material (Becker et al., 1999). Here, aluminum, phosphorus and germanium are most often used as additives to silica. Furthermore, the dopant, such as erbium, which is crucial for the amplifying property, also needs to be injected to the fiber preform material. This is most conveniently arranged by a flame-driven nanoparticle deposition process according to 
Fog. 7 9 . resulting in a deposit structure given in Fig. 5e. It isvalso important that when the generated deposit, the actual fiber preform, will be further processed into an optical fiber, having the presence of carbonaceous compounds minimized with the use of hydrogen flame is an advantage (Hotoleanu et al., 2002).

Other optical applications of LFS can be found in fabricating surface plasmon resonance materials (Saarinen et al., 2014). Finally, also functional coatings can be fabricated on glass surfaces, practically by the same mechanisms, using the LFS in a direct deposition process (Pimenoff et al., 2009; Piispanen et al., 2011).

\subsection{Functional coatings}

In the past 10 years, the Liquid Flame Spray method has been applied to prepare functional coatings by utilizing direct deposition of the nanoparticles from the flame onto the substrate. One of the conventional uses of nanoparticles is catalysis, as described by e.g. Johannessen et al. (2004), where methane was used as fuel to fabricate noble metal based nanoparticles. The LFS has also been used in a somewhat similar application (Keskinen et al., 2007b; Aromaa et al. 2013). Photocatalytic coatings have been fabricated by Keskinen et al. (2005) and Keskinen et al. (2006).

Recently, a slightly less conventional application of the LFS method as a functional coating process has been introduced, where $\mathrm{TiO}_{2}$ or $\mathrm{SiO}_{2}$ nanoparticles are deposited onto heat sensitive materials, such as paper or paperboard, in a roll-to-roll scheme, in order to control the wetting of the surface (Teisala et al., 2010; Mäkelä et al., 2011; Stepien et al., 2011; Teisala et al., 2014a; Haapanen et al., 2015). Here, a layer of nanoparticles, with structure and morphology described in Fig. 5e has been created. The feasible line speeds for the process are between 50 $500 \mathrm{~m} / \mathrm{min}$. In the process, the LFS flame is directed towards the moving paperboard. From the model calculations (Aromaa et al., 2012) and from the paper surface temperature measurements using a pyrometer, the surface temperature of the paperboard has been estimated to remain below $300{ }^{\circ} \mathrm{C}$. The nanoparticle flux from the flame $\left(\mathrm{T}=600-800^{\circ} \mathrm{C}\right.$ ) onto the paperboard is estimated to be caused mostly by thermophoresis. A SEM-graph of the porous layer, consisting of ca. $20 \mathrm{~nm} \mathrm{TiO}$ nanoparticles, is shown in Fig. 8. According to the analysis of Stepien et al. (2013a), the thickness of the porous coating in the as-prepared form is approximately $600 \mathrm{~nm}$, but the layer can be solidified by a heavy mechanical compression.

Both superhydrophilic (Tuominen et al., 2014) and superhydrophobic (Teisala et al., 2012; Stepien et al., 2012a; Stepien et al., 2012b; Stepien et al., 2013a), coatings have been fabricated using $\mathrm{SiO}_{2}$ and $\mathrm{TiO}_{2}$, respectively. Additionally, their mechanical properties have been tested

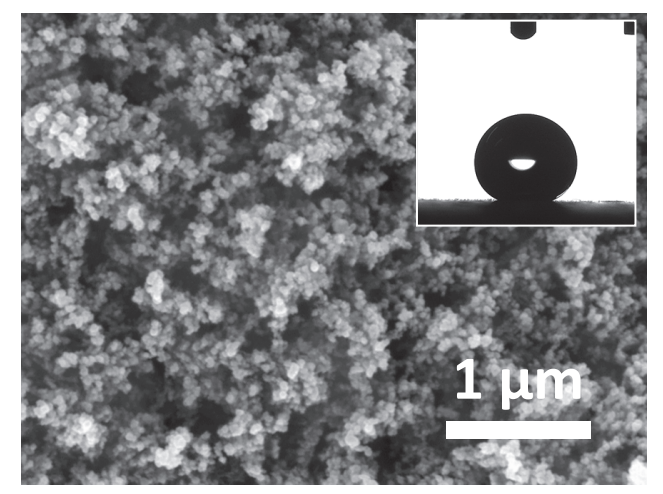

Fig. 8 The porous structure of superhydrophobic $\mathrm{TiO}_{2}$ nanoparticle deposit on a paperboard (see e.g. Teisala et al. (2014a) and references from thereon). Insert: water droplet on the superhydrophobic paperboard.

(Stepien et al. 2013b; Stepien et al. 2013c), and surface chemistry have been characterized (Stepien et al., 2012a; Stepien et al., 2013a). The results indicate that to achieve, e.g., a full superhydrophobicity on the coating, both surface chemistry and a hierarchical micro-nanostructure is required (Teisala et al., 2012; 2013b). Most interestingly, it is possible to convert the superhydrophobic $\mathrm{TiO}_{2}$ surface reversibly into superhydrophilic with UV illumination, and back to superhydrophobic with a heat treatment (Teisala et al., 2013a; Teisala et al., 2014b). Surface analysis has shown (Stepien et al., 2013a) that when the coating has been deposited on a paper or a paperboard, there seems to be a layer of carbonaceous compounds on the $\mathrm{TiO}_{2}$ nanoparticles, which will be chemically converted due to UV. The result has been interpreted so that the flame vaporises some carbonaceous material from the substrate, which will re-condense on the particles, and thereby the surface of the nanoparticles is chemically altered. This indicates that the coating process itself may play a central role in affecting the functionality of the coating.

This control of the switchable surface wetting of heat sensitive substrates, between superhydrophilic and superhydrophobic states, can be further applied in e.g. printability (Valtakari, et al., 2013) and microfluidistic design on roll-to-roll materials (Songok, et al., 2014; Valtakari et al., 2016). Also, hydrophobisation of the surface of wood materials is an important field (Moghaddam et al., 2013; Moghaddam et al., 2014), where direct nanoparticle deposition from the LFS has also been applied successfully (Moghaddam et al., 2015; Moghaddam et al., 2016). Superhydrophobic coatings can also be used to affect the corrosion properties of the surface (Ejenstam et al., 2013; Ejenstam et al., 2015a; Ejenstam et al., 2016), with a potential application field also for nanoparticle coatings (Ejenstam et al., 2015b). 
1593-1609.

Bamford C.R., Color Generation and Control in Glass, Elsevier, Amsterdam, 1977.

We have presented results obtained during the past years on the several applications of the Liquid Flame Spray. As one type of a flame spray pyrolysis, it may be considered to be a conventional method for generating nanopowders from liquid precursors, even though it can utilize a wider range of available precursor compounds due to the help from the hydrogen combustion. Furthermore, due to its characteristics it can easily be applied in direct nanoparticle coating process of even a larger area, and moreover, the combustion product being water vapour instead of carbonaceous compounds gives a clear advantage in specific applications.

\section{Acknowledgements}

The authors wish to acknowledge funding from Academy of Finland, project nLABS 2014-2018, and from Finnish Funding Agency for Innovation (Tekes), project NANORATA2 (2011-2014) grant no. 40094/11. The research leading to these results has also received funding from European Union's Seventh Framework Programme FP7/2007-2013/under REA grant agreements $n^{\circ}$ [CP-IP 211464-2] (NANODEVICE 2009-2013) and $n^{\circ}$ [280765] (BUONAPART-E 2012-2016). The article reflects only the authors' view and that the Union is not liable for any use that may be made of the information contained therein.

\section{References}

Aromaa M., Keskinen H., Mäkelä J.M., The effect of process parameters on the Liquid Flame Spray generated titania nanoparticles, Biomolecular Engineering, 24 (2007) 543548.

Aromaa M., Arffman A., Suhonen H., Haapanen J., Keskinen J., Honkanen M., Nikkanen J.-P., Levänen E., Messing M.E., Deppert K., Teisala H., Tuominen M., Kuusipalo J., Stepien M., Saarinen J.J., Toivakka M., Mäkelä J.M., Atmospheric synthesis of superhydrophobic $\mathrm{TiO}_{2}$ nanoparticle deposits in a single step using Liquid Flame Spray, Journal of Aerosol Science, 52 (2012) 57-68.

Aromaa M., Pimenoff J.A., Mäkelä, J.M., Liquid Flame Spray as a means to achieve nanoscale coatings with easy-toclean properties, in: Daoud W.A. (Ed.), Self-Cleaning Materials and Surfaces: A Nanotechnology Approach, John Wiley \& Sons Ltd, Chichester, 2013, pp. 229-252.

Asbach C. Kaminski H., Fissan H., Monz C., Dahmann D., Mülhopt S., Paur H.-R., Kiesling H.J., Herrmann F., Voetz M., Kuhlbusch T.A.J., Comparison of four mobility particle sizers with different time resolution for stationary exposure measurements, Journal of Nanoparticle Research, 11 (2009)

Becker P., Olsson N.A., Simpson J.R., Erbium-Doped Fiber Amplifiers: Fundamentals and Technology, Academic Press, San Diego, 1999.

Beneq Oy, 2016, Glass Coloration <http://beneq.com/ glass-coloration.html $>$ accessed 15.05.2016.

Blattmann C.O., Sotiriou G.A., Pratsinis S.E., Rapid synthesis of flexible conductive polymer nanocomposite films, Nanotechnology, 26 (2015) 125601.

Brouwer D., van Duuren-Stuurman B., Berges M., Jankowska E., Bard D., Mark D., From workplace air measurement results toward estimates of exposure? Development of a strategy to assess exposure to manufactured nano-objects, Journal of Nanoparticle Research, 11 (2009) 1867-1881.

Castillo J.L., Martin S., Rodriguez-Perez D., Perea A., GarciaYbarra P.-L., Morphology and nanostructure of granular materials built from nanoparticles, KONA Powder and Particle Journal, 31 (2014) 214-233.

Cho J., Choi M., Determination of number density, size and morphology of aggregates in coflow diffusion flames using light scattering and local sampling, Journal of Aerosol Science, 31 (2000) 1077-1095.

Chung S.-L., Katz J.L., The counterflow diffusion flame burner: A new tool for the study of the nucleation of refractory compounds, Combustion and Flame, 61 (1985) 271-284.

Dosev D. Guo B., Kennedy I.M., Photoluminescence of $\mathrm{Eu}^{3+}$ : $\mathrm{Y}_{2} \mathrm{O}_{3}$ as an indication of crystal structure and particle size in nanoparticles synthesized by flame spray pyrolysis, J. Aerosol Sci., 37 (2006) 402-411.

Ejenstam L., Ovaskainen L., Rodriguez-Meizoso I., Wågberg L., Pan J., Swerin A., Claesson P.M., The effect of superhydrophobic wetting state on corrosion protection - The AKD example, Journal of Colloid and Interface Science, 412 (2013) 56-64.

Ejenstam L., Swerin A., Pan J., Claesson P.M., Corrosion protection by hydrophobic silica particle-polydimethylsiloxane composite coatings, Corrosion Science, 99 (2015a) 89-97.

Ejenstam L., Tuominen M., Haapanen J., Mäkelä J.M., Pan J., Swerin A., Claesson, P.M., Long-term corrosion protection by a thin nano-composite coating, Applied Surface Science, 357 (2015b) 2333-2342.

Ejenstam L., Swerin A., Claesson P.M., Toward superhydrophobic polydimethylsiloxane-silica particle coatings, Journal of Dispersion Science and Technology, 37 (2016) 1375-1383.

Goldys E.M., Drozdowicz-Tomsia K., Jinjun S., Dosev D., Kennedy I.M., Yatsunenko S., Godlewski M., Optical Characterization of Eu-Doped and Undoped $\mathrm{Gd}_{2} \mathrm{O}_{3}$ Nanoparticles Synthesized by the Hydrogen Flame Pyrolysis Method, J. Am. Chem. Soc., 128 (2006) 14498-14505.

Gross K.A., Tikkanen J. Keskinen J., Pitkänen V., Eerola M., Siikamäki R., Rajala M., Liquid flame spraying for glass coloring, Journal of Thermal Spray Technology, 8 (1999) 583-589.

Haapanen J., Aromaa M., Teisala H, Tuominen M., Stepien M., Saarinen J.J., Heikkilä M.J., Toivakka M., Kuusipalo J., Mäkelä J.M., Binary $\mathrm{TiO}_{2} / \mathrm{SiO}_{2}$ nanoparticle coating for 
$d e^{r}$ confrolling the wetting properties of paperboard, Materials WChemistry and Physics, 149-150 (2015) 230-237.

Hannebauer B., Menzel F., The Combustion of $\mathrm{SiCl}_{4}$ in $\mathrm{Hot}_{2} /$ $\mathrm{H}_{2}$ flames, Z. Anorg. Chem, 629 (2003) 1485-1490.

Harra J., Nikkanen J.-P., Aromaa M. Suhonen H., Honkanen M., Salminen T., Heinonen S., Levänen E., Mäkelä J.M., Gas phase synthesis of encapsulated iron oxide-titanium dioxide composite nanoparticles by spray pyrolysis, Powder Technology, 243 (2013) 46-52.

Harra J., Juuti P., Haapanen J., Sorvali M., Roumeli E., Honkanen M., Vippola M., Yli-Ojanperä J., Mäkelä J.M., Coating of silica and titania aerosol nanoparticles by silver vapor condensation, Aerosol Science and Technology, 49 (2015) 767776.

Harra J., Kujanpää S., Haapanen J., Juuti P., Hyvärinen L., Honkanen M., Mäkelä J.M., Aerosol Analysis of Residual and Nanoparticle Fractions from Spray Pyrolysis of Poorly Volatile Precursors. Accepted manuscript online: 11 AUG 2016 11:40PM EST | DOI: 10.1002/aic.15449.

Hartmann W., Mangold H., Kerner D., Flame-hydrolytically produced titanium dioxide mixed oxide, method of its production and its use, US Patent, (1995) 5451390 A.

Hotoleanu M., Kiiveri P., Tammela S., Särkilahti S., Valkonen H., Rajala M., Kurki J., Janka K., Characteristics of highly doped Er-fibers manufactured by the new direct nanoparticle deposition process, in: 7th European Conference on Networks \& Optical Communications (NOC2002), Darmstadt, 2002, pp. 200-204.

Jang H.D., Chang H., Suh Y., Okuyama K., Synthesis of $\mathrm{SiO}_{2}$ nanoparticles from sprayed droplets of tetraethylorthosilicate by the flame spray pyrolysis, Current Applied Physics, 6, Supplement 1 (2006) e110-e113.

Johannessen T., Jensen J.R., Mosleh M., Johansen J., Quaade U., Livbjerg H., Flame synthesis of nanoparticles: Applications in catalysis and product/process engineering. Chemical Engineering Research and Design, 82 (2004) 1444-1452.

Kammler H.K., Mädler L., Pratsinis S.E., Flame synthesis of nanoparticles, Chemical Engineering \& Technology, 24 (2001a) 583-596.

Kammler, H.K., Mueller, R., Senn, O., Pratsinis, S.E., Synthesis of silica-carbon particles in a turbulent $\mathrm{H}_{2}$-air flame aerosol reactor. AIChE Journal, 47 (2001b) 1533-1543.

Katusic S., Kress P., Method for producing mixed oxides comprising lithium, Patent, (2011) CA2803211 A1.

Keskinen H., Mäkelä J.M., Vippola M., Nurminen M., Liimatainen J., Lepistö T., Keskinen, J., Generation of silver/ palladium nanoparticles by liquid flame spray. Journal of Materials Research, 19 (2004) 1544-1550.

Keskinen H., Mäkelä J.M., Hellsten S., Aromaa M., Levänen E., Mäntylä T., 2005. Generation of titania nanoparticles by liquid flame spray for photocatalytic applications, in: Devi A., Fischer R., Parala H., Allendorf M., Hitchman M. (Eds.), EUROCVD-15: Fifteenth European Conference on Chemical Vapor Deposition, The Electrochemical Society, Inc., Pennington, 2005, pp. 491-498.

Keskinen H., Mäkelä J.M., Aromaa M., Keskinen J., Areva S., Teixeira C.V., Rosenholm J.B., Pore V., Ritala M., Leskelä M., Raulio M., Salkinoja-Salonen M.S., Levänen E.,
Mäntylä T., Titania and titania-silver nanoparticle deposits by Liquid Flame Spray and their functionality as photocatalyst for organic- and biofilm removal, Catalysis Letters, 111 (2006) 127-132.

Keskinen H., Mäkelä J.M, Aromaa M., Ristimäki J., Kanerva T., Levänen E., Mäntylä T., Keskinen J., Effect of silver addition on the formation and deposition of titania nanoparticles produced by Liquid Flame Spray, Journal of Nanoparticle Research, 9 (2007a) 569-588.

Keskinen H., Mäkelä J.M., Heikkinen R., Suopanki A., Keskinen J., Synthesis of Pd-alumina and Pd-lanthana suspension for catalytic applications by one-step Liquid Flame Spray, Catalysis Letters, 119 (2007b) 172-178.

Keskinen H., Aromaa M., Heine M.-C., Mäkelä, J.M., Size and velocity measurements in sprays and particle producing flame sprays, Atomization and Sprays, 18 (2008) 1-26.

Keskinen H., Tricoli A., Marjamäki M., Mäkelä J.M., Pratsinis, S.E., Size-selected agglomerates of $\mathrm{SnO}_{2}$-nanoparticles as gas sensors, Journal of Applied Physics, 106 (2009) 084316.

Koivisto A.J., Aromaa M., Mäkelä J.M., Pasanen P., Hussein T., Hämeri K., Concept to estimate regional inhalation dose of industrially synthesized nanoparticles, ACS Nano, 6 (2012) $1195-1203$.

Koivisto A.J., Aromaa M., Koponen I.K., Fransman W., Jensen K.A., Mäkelä J.M., Hämeri K.J., Workplace performance of a loose-fitting powered air purifying respirator during nanoparticle synthesis, Journal of Nanoparticle Research, 17 (2015) 177-186.

Kruis F.E., Fissan H., Peled A., Synthesis of nanoparticles in the gas phase for electronic, optical and magnetic applications - a review, Journal of Aerosol Science, 29 (1998) 511535.

Kulkarni P., Baron P.A., Willeke K., Aerosol Measurement: Principles, Techniques, and Applications, John Wiley \& Sons, Inc., Hoboken, 2011.

Lee D., Choi M., Control of size and morphology of nano particles using $\mathrm{CO}_{2}$ laser during flame synthesis, Journal of Aerosol Science, 31 (2000) 1145-1163.

Liu G., Wong W.S.Y, Nasiri N, Tricoli A., Ultraporous superhydrophobic gas-permeable nano-layers by scalable solventfree one-step self-assembly Nanoscale, 8 (2016) 6085.

Mädler L., Liquid-fed aerosol reactors for one-step synthesis of nano-structured particles, KONA Powder and Particle Journal, 22 (2004) 107-120.

Mädler L., Roessler A., Pratsinis S.E., Sahm T., Gurlo A., Barsan N., Weimar U., Direct formation of highly porous gassensing films by in situ thermophoretic deposition of flamemade $\mathrm{Pt} / \mathrm{SnO}_{2}$ nanoparticles, Sensors and Actuators B, 114 (2006a) 283-295.

Mädler L., Lall A.A., Friedlander S.K., One-step aerosol synthesis of nanoparticle agglomerate films: Simulation of film porosity and thickness, Nanotechnology, 17 (2006b) 47834795.

Mäkelä J.M., Keskinen H., Forsblom T., Keskinen, J., Generation of metal and metal oxide nanoparticles by liquid flame spray process, Journal of Materials Science, 39 (2004) 2783-2788.

Mäkelä J.M., Unpublished results, Department of Physics, Tam- 
Nikkanen J.-P., Keskinen H., Aromaa M., Järn M., Kanerva T., Levänen E., Mäkelä J.M., Mäntylä T., Iron oxide doped alumina-zirconia nanoparticle synthesis by liquid flame spray from metal organic precursors, Research Letters in Nanotechnology, 2008 (2008) 516478.

Nikkanen J.-P., Harju M., Järn M., Linden J., Rintala J., Messing M.E., Huttunen-Saarivirta E., Saarinen T., Kanerva T., Honkanen M., Aromaa M., Levänen E., Pettersson M., Mäkelä J.M., Deppert K., Mäntylä T., Synthesis of carbon nanotubes on $\mathrm{Fe}_{\mathrm{x}} \mathrm{O}_{\mathrm{y}}$ doped $\mathrm{Al}_{2} \mathrm{O}_{3}-\mathrm{ZrO}_{2}$ nanopowder, Powder Technology, 266 (2014) 106-112.

Park H.K., Park K.Y., Control of particle morphology and size in vapor-phase synthesis of titania, silica and alumina nanoparticles, KONA Powder and Particle Journal, 32 (2015) 85-101.

Pimenoff J.A., Hovinen A.K., Rajala M.J., Nanostructured coatings by liquid flame spraying, Thin Solid Films, 517 (2009) 3057-3060.

Piispanen M., Hupa L., Comparison of self-cleaning properties of three titania coatings on float glass, Applied Surface Science, 258 (2011) 1126-1131.

Pikhitsa P.V., Choi M., Yang S., Kim J.-Y., Jang H., Park J.-H., Fast fragmentation of metal oxide nanoparticles via reduction in oxyhydrogen flame, Applied Physics Letters, 90 (2007) 163106.

Pitkänen A., Mäkelä J.M., Nurminen M., Oksanen A., Janka K., Keskinen J., Keskinen H., Liimatainen J.K., Hellstén S., Määttä T., Numerical study of silica particle formation in turbulent $\mathrm{H}_{2} / \mathrm{O}_{2}$ flame, IFRF Combustion Journal, (2005) 200509.

Pratsinis S.E., Flame aerosol synthesis of ceramic powders, Progress in Energy and Combustion Science, 24 (1998) 197-219.

Purwanto A., Wang W.-N., Okuyama K., Flame Spray Pyolysis in: Ashgriz. N. (Ed.), Handbook of Atomization and Sprays, Springer, New York, 2011, pp. 869-879.

Rajala M., Janka K., Kykkänen P., An industrial method for nanoparticle synthesis with a wide range of compositions, Reviews on Advanced Materials Science, 5 (2003) 493-497.

Rosebrock C.D., Riefler N., Wriedt T., Mädler L., Tse S.D., Disruptive burning of precursor/solvent droplets in flame-spray synthesis of nanoparticles, AIChE Journal, 59 (2013) 45534566.

Rosebrock C.D., Wriedt T., Mädler L., Wegner K., The role of microexplosions in flame spray synthesis for homogeneous nanopowders from low-cost metal precursors, AIChE Journal, 62 (2016) 381-391.

Saarinen J.J., Valtakari D., Haapanen J., Salminen T., Mäkelä J.M., Uozumi J., Surface-enhanced Raman scattering active substrates by liquid flame spray deposited and inkjet printed silver nanoparticles, Optical Review, 21 (2014) 339-344.

Sainiemi L., Keskinen H., Aromaa M., Luosujärvi L., Grigoras K., Kotiaho T., Mäkelä J.M., Franssila S., Rapid fabrication of high aspect ratio silicon nanopillars for chemical analysis, Nanotechnology, 18 (2007) 505303. DOI:10.1088/09574484/18/50/505303.

Sheen S., Yang S., Jun K., Choi M., One-step flame method for 
and or.

thersynthesis of coated composite nanoparticles, Journal of WNanoparticle Research, 11 (2009) 1767-1775.

Sokolowski M., Sokolowska A., Michalski A., Gokieli B., The "in-flame-reaction" method for $\mathrm{Al}_{2} \mathrm{O}_{3}$ aerosol formation, Journal of Aerosol Science, 8 (1977) 219-230.

Songok J., Tuominen M., Teisala H., Haapanen J., Mäkelä J.M., Kuusipalo J., Toivakka M., Paper-based microfluidistics: Fabrication technique and dynamics of capillary-driven surface flow, ACS Applied Materials \& Interfaces, 6 (2014) 20060-20066.

Sotiriou G.A., Blattmann C.O., Pratsinis S.E., Flexible, Multifunctional, Magnetically Actuated Nanocomposite Films, Advanced Functional Materials, 23 (2013) 34-41.

Stark W.J., Pratsinis S.E., Aerosol flame reactors for manufacture of nanoparticles, Powder Technology, 126 (2002) 103108.

Stepien M., Saarinen J.J., Teisala H., Tuominen M., Aromaa M., Kuusipalo J., Mäkelä J.M., Toivakka M., Adjustable wettability of paperboard by liquid flame spray process, Applied Surface Science, 257 (2011) 1911-1917.

Stepien M., Saarinen J.J., Teisala H., Tuominen M., Aromaa M., Kuusipalo J., Mäkelä J.M., Toivakka M., Surface chemical analysis of photocatalytic wettability conversion of $\mathrm{TiO}_{2}$ nanoparticle coating, Surface and Coatings Technology, 208 (2012a), 73-79.

Stepien M., Saarinen J.J., Teisala H., Tuominen M., Aromaa M., Kuusipalo J., Mäkelä J.M., Toivakka M., Surface chemical characterization of nanoparticle coated paperboard, Applied Surface Science, 258 (2012b) 3119-3125.

Stepien M., Saarinen J. J., Teisala H., Tuominen M., Aromaa M., Haapanen J., Kuusipalo J., Mäkelä J.M., Toivakka M., ToFSIMS analysis of UV-switchable $\mathrm{TiO}_{2}$-nanoparticle-coated papersurface, Langmuir, 29 (2013a) 3780-3790.

Stepien M., Chinga-Carrasco G., Saarinen J.J., Teisala H., Tuominen M., Aromaa M., Haapanen J., Kuusipalo J., Mäkelä J.M., Toivakka, M., Wear resistance of nanoparticle coatings on paperboard, Wear, 307 (2013b) 112-118.

Stepien M., Saarinen J.J., Teisala H., Tuominen M., Haapanen J. Mäkelä J.M., Kuusipalo J, Toivakka M., Compressibility of porous $\mathrm{TiO}_{2}$ nanoparticle coating on paperboard, Nanoscale Research Letters, 8 (2013c) 444-449.

Stepuk A., Krämer K., Stark, W.J., Flame synthesis of complex fluoride-based nanoparticles as upconversion phosphors, KONA Powder and Particle Journal, 30 (2013) 267-275.

Strobel R., Pratsinis S.E., Effect of solvent composition on oxide morphology during flame spray pyrolysis of metal nitrates, Physical Chemistry Chemical Physics, 13 (2011) 9246-9252.

Tammela S., Söderlund M, Koponen J., Philippov V., Stenius, P., The potential of direct nanoparticle deposition for the next generation of optical fibers, in: Digonnet M.J., Jiang S. (Eds.), Proceedings of SPIE 6116, Optical Components and Materials III, Society of Photo-Optical Instrumentation Engineers, San Jose, 2006, 61160G.

Teisala H., Tuominen M., Aromaa M., Mäkelä J.M., Stepien M., Saarinen J.J., Toivakka M., Kuusipalo, J., Development of superhydrophobic coating on paperboard surface using the Liquid Flame Spray, Surface and Coatings Technology, 205
(2010) 436-445.

Teisala H., Tuominen M., Aromaa M., Stepien M., Mäkelä J.M., Saarinen J.J., Toivakka M., Kuusipalo J., Nanostructures increase water droplet adhesion on hierarchically rough superhydrophobic surfaces, Langmuir, 28 (2012) 31383145 .

Teisala H., Tuominen M., Stepien M., Haapanen J., Mäkelä J.M., Saarinen J.J., Toivakka M., Kuusipalo J., Wettability conversion on the liquid flame spray generated superhydrophobic $\mathrm{TiO}_{2}$ nanoparticle coating on paper and board by photocatalytic decomposition of spontaneously accumulated carbonaceous overlayer, Cellulose, 20 (2013a) 391-408.

Teisala H., Tuominen M., Aromaa M., Stepien M., Mäkelä J.M., Saarinen J.J., Toivakka M., Kuusipalo J., High- and lowadhesive superhydrophobicity on the liquid flame spraycoated board and paper: structural effects on surface wetting and transition between the low- and highadhesive states, Colloid and Polymer Science, 291 (2013b) 447-455.

Teisala H., Tuominen M., Haapanen J., Aromaa M., Stepien M., Mäkelä J.M., Saarinen J.J., Toivakka M., Kuusipalo J., Review on Liquid Flame Spray in paper converting: Multifunctional superhydrophobic nanoparticle coatings, Nordic Pulp and Paper Research Journal, 29 (2014a) 747-759.

Teisala H., Tuominen M., Haapanen J., Aromaa M., Stepien M., Mäkelä J.M., Saarinen J.J., Toivakka M, Kuusipalo J., Switchable water absorption of paper via liquid flame spray nanoparticle coating, Cellulose, 21 (2014b) 2033-2043.

Teoh W., Amal R., Mädler, L., Flame spray pyrolysis: An enabling technology for nanoparticles design and fabrication, Nanoscale, 2 (2010) 1324-1347.

Thimsen E., Biswas P. Nanostructured photoactive films synthesized by a flame aerosol reactor, AIChE Journal, 53 (2007) 1727-1735.

Thimsen E., Rastgar N., Biswas P., Nanostructured $\mathrm{TiO}_{2}$ films with controlled morphology synthesized in a single step process: Performance of dye-sensitized solar cells and photo water splitting, Journal of Physical Chemistry C, 112 (2008) 4134-4140.

Tikkanen J., Eerola M., Rajala M., Coating glass by flame spraying, Journal of Non-Crystalline Solids, 178 (1994) 220-226.

Tikkanen J., Gross K.A., Berndt C.C., Pitkänen V., Keskinen J., Raghu S., Rajala M. Karthikeyan J., Characteristics of the liquid flame spray process. Surface and Coatings Technology, 90 (1997) 210-216.

Tricoli A., Graf M., Mayer F., Kühne S., Hierlemann A., Pratsinis S.E., Micropatterning layers by flame aerosol deposition-annealing, Advanced Materials, 20 (2008) 30053010.

Trommer R.M., Bergmann C.P., Flame Spray Technology: Method for Production of Nanopowders, Springer, Berlin 2015 .

Tuominen M., Teisala H., Aromaa M., Stepien M., Mäkelä J.M., Saarinen J.J., Toivakka M., Kuusipalo J., Creation of superhydrophilic surfaces of paper and board, Journal of Adhesion Science and Technology, 28 (2014) 864-879.

Ulrich D.G., Theory of particle formation and growth in oxide 
al $\partial^{\circ}$

sykthesis flames, Combustion Science and Technology, 4 No(1971) 47-57.

Ulrich G.D., Flame synthesis of fine particles, Chemical \& Engineering News, 62 (1984) 22-29.

Valtakari D., Bollström R., Tuominen M., Teisala H., Aromaa

M., Toivakka M., Kuusipalo J., Mäkelä J.M., Uozumi J., Saarinen, J.J., Flexographic printing of PEDOT: PSS on coated papers for printed functionality, Journal of Print Media and Technology Research, 2 (2013) 7-13.

Valtakari D., Stepien M., Haapanen J., Teisala H., Tuominen M., Kuusipalo J., Mäkelä J.M., Toivakka M., Saarinen J.J., Planar fluidic channels on $\mathrm{TiO}_{2}$ nanoparticle coated paperboard, Nordic Pulp and Paper Research Journal, 31 (2016) $232-238$.

\section{Author's short biography}
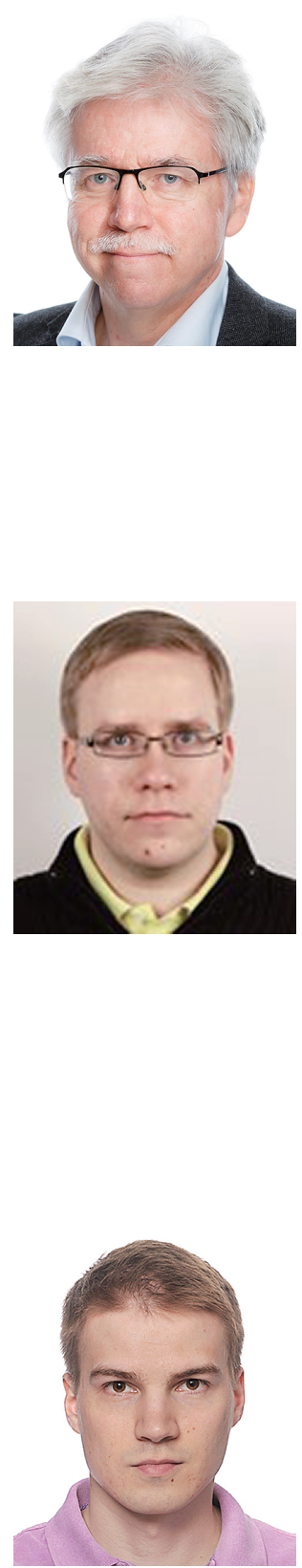

\section{Jyrki M. Mäkelä}

Dr. Jyrki M. Mäkelä is Professor at the Department of Physics, Tampere University of Technology, Finland. He graduated from University of Helsinki, Department of Physics in 1987 and took the degree of PhD at the same department in 1992. During 1992-2000 he worked in the Aerosol Physics Group at University of Helsinki on nanoparticle measurement, mainly in chamber studies and for atmospheric nanoparticle formation. In 2000 he moved to Tampere University of Technology, TUT, as a Lecturer and received a full Professorship there in 2010. Since 2000 he has been leading the Aerosol Synthesis Group at TUT, Aerosol Physics Laboratory, focusing on nanoparticle generation and fabrication of functional surfaces via aerosol synthesis. During 2014-2016 he acted as the Head of the Department of Physics at TUT.

\section{Janne Haapanen}

Janne Haapanen is currently working as a researcher and a doctoral student at Tampere University of Technology, Department of Physics, Aerosol Physics Laboratory. He has been working in Prof. Mäkelä's Aerosol Synthesis group since 2009. He received his MSc (Tech.) degree in Technical Physics in 2010 and currently working a researcher and a doctoral student in the same research group. During 2015-2016, he worked as a visiting researcher at Danish Technological Insititute, Aarhus, Denmark and at Technical University of Denmark, Kgs. Lyngby, Denmark for 7 months. Main topic of research is functional nanocoatings fabricated by Liquid Flame Spray (LFS) method. He has done research in antibacterial, photocatalytic, superhydrophobic, superhydrophilic, ice-phobic and superamphiphobic nanocoatings by combining several methods with LFS, such as plasma treatment, ALD and silanization.

\section{Juha Harra}

Dr. Juha Harra is currently a postdoctoral researcher at the Department of Physics in Tampere University of Technology. He received his Master of Science (Technology) and Doctor of Science (Technology) degrees in Technical Physics from Tampere University of Technology in 2010 and 2015, respectively. During 2016, he worked six months as a visiting scientist in SP Technical Research Institute of Sweden at the Department of Chemistry, Materials and Surfaces in Stockholm. His main research interest is in aerosol physics, including nanoparticle synthesis using gas-phase techniques, real-time measurement of aerosol particles, and particle deposition for functional nanocoatings. 


\section{Author's short biography}

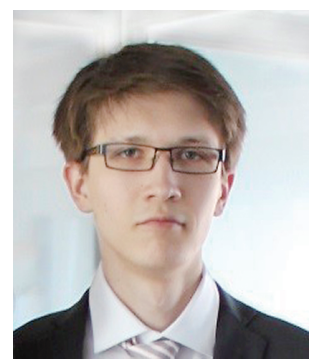

\section{Paxton Juuti}

Paxton Juuti is presently studying Technical Physics as a doctoral student at the Department of Physics, Tampere University of Technology, Finland. He received his BSc (Tech.) degree in 2013 on the topic of nanoparticle sintering and MSc (Tech.) degree in 2015 on real-time monitoring of aerosol synthesis. His research interests include material functionalization via aerosol routes and monitoring of aerosol processes.

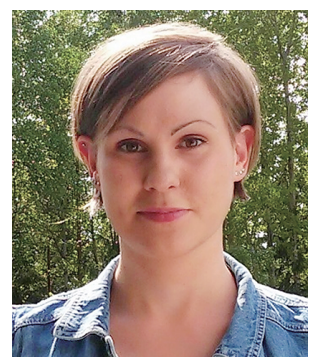

\section{Sonja Kujanpää}

MSc (Teck.) Sonja Kujanpää graduated from Tampere University of Technology majoring in Advanced Engineering Physics in 2016. The topic of her thesis was "Determination of the mass size distribution of the industrial nanoparticle application produced aerosol". Today she works as a teacher of mathematical subjects in comprehensive school. 